facilitate rapid implementation of the intervention in large numbers of patients by the clinical staff at different institutions, all in the chaos of emergency departments; and to avoid potential responder bias in the outcome assessments of patients (or surrogates) who may have thought they had received "nonstandard" care. Our decision to view the matter of head position as involving "low risk" was based on several considerations: the insufficient amount of level 1 evidence specifying the benefits and harms of head positioning for patients with acute stroke; the fact that people change their head position within the ranges being tested during routine hospital care and in daily life, as they shift from activity during the day to rest and sleep at night; and the view that patient care would not be compromised by either of the interventions.

Finally, Taito and Yamauchi raise an important point regarding an unresolved issue that should be addressed in another trial - that of the appropriate timing (and intensity) of early mobilization after acute stroke that follows from the unexpected results of the AVERT trial. ${ }^{2}$ Unfortunately, we did not collect data on the specific time that patients began to move outside the confines of the bed.

Craig S. Anderson, Ph.D.

University of New South Wales

Sydney, NSW, Australia

canderson@georgeinstitute.org.cn

Tom Robinson, M.D.

University of Leicester

Leicester, United Kingdom

Caroline Watkins, Ph.D.

University of Central Lancashire

Preston, United Kingdom

Since publication of their article, the authors report no further potential conflict of interest.

1. National statement on ethical conduct in human research (2007) — updated May 2015. Canberra, ACT: National Health and Medical Research Council, Australian Research Council and Australian Vice-Chancellors Committee, Commonwealth of Australia (https://www.nhmrc.gov.au/guidelines/publications/e72).

2. AVERT Trial Collaboration Group. Efficacy and safety of very early mobilisation within $24 \mathrm{~h}$ of stroke onset (AVERT): a randomised controlled trial. Lancet 2015;386:46-55.

DOI: 10.1056/NEJMc1709517

\title{
Transplanting HCV-Infected Kidneys into Uninfected Recipients
}

TO THE EDITOR: Goldberg et al. (June 15 issue) ${ }^{1}$ report cure of hepatitis $\mathrm{C}$ virus (HCV) infection, after transplantation of kidneys infected with HCV (genotype 1) into HCV-negative recipients, with the use of a 12-week course of elbasvirgrazoprevir. However, data on other types of solid-organ transplantation are lacking. Here, we report cure of HCV infection after accidental transmission of HCV from one organ donor to five different recipients (Table 1). The 55-year-old female donor did not belong to a group considered to be at high risk for HCV infection, and routine testing for anti-HCV IgG was negative. However, retrospective analysis revealed lowlevel HCV RNA (genotype 1a) viremia. All the transplant recipients were $\mathrm{HCV}$-negative before transplantation and had development of HCV viremia in the early post-transplantation period. A 12-week course of different sofosbuvir-based anti-HCV regimens ${ }^{2-4}$ was used to treat four of the patients. The liver-transplant recipient died from septic shock early after transplantation, before treatment could have been initiated. All four recipients who received treatment currently have stable graft function and cure of HCV infection (sustained virologic response at week 12 after treatment).

In summary, we contribute further evidence that the early initiation of a sofosbuvir-based regimen is an efficient and safe treatment option in the context of different types of solidorgan transplantation from an HCV-positive donor to an HCV-negative recipient.

Fabian Halleck, M.D

Klemens Budde, M.D.

Michael Duerr, M.D.

Oliver Staeck, M.D.

Joerg Hofmann, M.D.

Charité-Universitätsmedizin Berlin

Berlin, Germany

fabian.halleck@charite.de

Ute Eisenberger, M.D.

Kerstin Herzer, M.D.

University Duisburg-Essen

Essen, Germany 


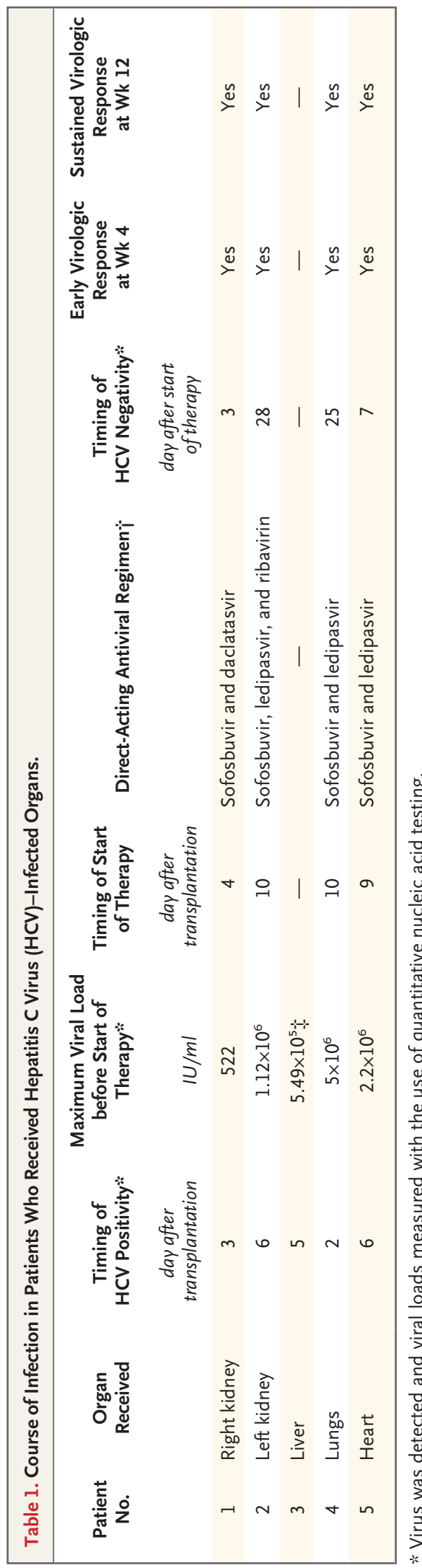

Martina Sterneck, M.D.

University Medical Center Hamburg-Eppendorf

Hamburg, Germany

Jens Gottlieb, M.D.

Hannover Medical School

Hannover, Germany

Uwe Schulz, M.D.

Heart and Diabetes Center NRW

Bad Oeynhausen, Germany

No potential conflict of interest relevant to this letter was reported.

1. Goldberg DS, Abt PL, Blumberg EA, et al. Trial of transplantation of HCV-infected kidneys into uninfected recipients. N Engl J Med 2017;376:2394-5.

2. Sawinski D, Kaur N, Ajeti A, et al. Successful treatment of hepatitis $\mathrm{C}$ in renal transplant recipients with direct-acting antiviral agents. Am J Transplant 2016;16:1588-95.

3. Kamar N, Marion O, Rostaing L, et al. Efficacy and safety of sofosbuvir-based antiviral therapy to treat hepatitis C virus infection after kidney transplantation. Am J Transplant 2016;16: 1474-9.

4. Eisenberger U, Guberina H, Willuweit K, et al. Successful treatment of chronic hepatitis $\mathrm{C}$ virus infection with sofosbuvir and ledipasvir in renal transplant recipients. Transplantation 2017;101:980-6.

DOI: 10.1056/NEJMc1709315

TO THE EDITOR: Goldberg and colleagues demonstrated that HCV-positive kidneys can be successfully used for transplantation in HCV-negative recipients. Likewise, the livers of many HCV-positive donors are of good quality and can be transplanted, with outcomes similar to those obtained with HCV-negative livers. In 2015, however, 11\% of procured HCV-positive livers were discarded. ${ }^{1}$ The new direct-acting antiviral agents have dramatically changed the landscape of HCV treatment, with sustained virologic response rates of up to $95 \%$, independent of HCV genotype, stage of fibrosis, or previous response to antiviral therapy. ${ }^{2,3}$ The use of HCV-positive livers could substantially decrease waiting time and mortality among HCV-negative patients on the transplant waiting list. Clinical trial data on intentional transplantation of HCV-positive livers into HCVnegative recipients are lacking. HCV-negative patients who have, without the knowledge of the physician, received HCV-positive livers have had good responses to treatment. ${ }^{4}$ In our center, we have successfully performed two intentional transplantations of HCV-positive livers into HCV-negative recipients. In light of the new HCV treatment options available, it is unethical to let HCV-negative patients die while many usable HCV-positive 
liver grafts are discarded. It is now time to challenge dogmatic beliefs and the current transplant-allocation algorithm.

Paulo N. Martins, M.D., Ph.D.

Babak Movahedi, M.D., Ph.D.

Adel Bozorgzadeh, M.D.

University of Massachusetts

Worcester, MA

paulo.martins@umassmemorial.org

No potential conflict of interest relevant to this letter was reported.

1. Bowring MG, Kucirka LM, Massie AB, et al. Changes in utilization and discard of hepatitis C-infected donor livers in the recent era. Am J Transplant 2017;17:519-27.

2. Coilly A, Samuel D. Pros and cons: usage of organs from donors infected with hepatitis $\mathrm{C}$ virus - revision in the directacting antiviral era. J Hepatol 2016;64:226-31.

3. Levitsky J, Verna EC, O'Leary JG, et al. Perioperative ledipasvirsofosbuvir for HCV in liver-transplant recipients. N Engl J Med 2016;375:2106-8.

4. Suryaprasad A, Basavaraju SV, Hocevar SN, et al. Transmission of hepatitis $\mathrm{C}$ virus from organ donors despite nucleic acid test screening. Am J Transplant 2015;15:1827-35.

DOI: 10.1056/NEJMc1709315

THE AUTHORS REPLY: Halleck et al. describe five patients who were infected with HCV after transplantation with organs from a deceased donor in whom HCV infection had not been suspected. Four recipients survived the early post-transplantation period and were cured of HCV infection. Their experience adds to the small but growing body of evidence indicating that transplantationrelated immunosuppression does not substantially diminish the effectiveness of direct-acting antiviral agents for HCV treatment. ${ }^{1}$ The donor's profile also offers a cautionary tale: risk stratification for bloodborne viral infections has limited value, because this stratification is based on whatever information happens to be available about the donor's social and medical history. We advocate that all organ donors undergo nucleic acid screening for HCV and HIV infection, which is more sensitive than antibody testing and has enhanced relevance during this era of widespread and sometimes unsuspected opiate abuse in many places, including the United States. ${ }^{2}$

Martins et al. report two instances in which $\mathrm{HCV}$-infected livers were intentionally used for transplantation into HCV-negative recipients. We support continued study of this practice, which we believe should not yet be the standard of care. Research oversight is appropriate. Most candidates for transplantation know little about HCV. The risks of complications and noncure after new
HCV transmission during transplantation are uncertain. Therefore, robust processes of informed consent that acknowledge the unknown magnitude of risks are needed. Centers should collaborate, develop best practices, and publish on their experience with transplanting HCV-infected organs into HCV-negative patients. ${ }^{3}$

The biggest impediment to expanding the use of HCV-infected organs in some nations is guaranteeing access to expensive antiviral therapy. Leaders of transplantation programs and professional societies must work with payers to prospectively authorize treatment, so that patients who consent to donor-derived HCV infection are assured of timely therapy. In addition, the selection of antiviral therapy requires consideration of the viral genotype and interactions with commonly used drugs after transplantation. Renal insufficiency is also common with transplantation, and this may complicate the safe use of antivirals, including sofosbuvir; acute kidney injury occurs among more than a third of liver-transplant recipients specifically. ${ }^{4}$ Although we are optimistic that HCV-infected organs will expand the donor pool substantially, more data are needed to define the safest and most effective use of these organs for recipients who do not have HCV infection.

David S. Goldberg, M.D.

Peter L. Abt, M.D.

Peter P. Reese, M.D.

University of Pennsylvania Perelman School of Medicine

Philadelphia, PA

peter.reese@uphs.upenn.edu

\section{for the THINKER Trial Investigators}

Since publication of their letter, the authors report no further potential conflict of interest.

1. Sawinski D, Kaur N, Ajeti A, et al. Successful treatment of hepatitis $\mathrm{C}$ in renal transplant recipients with direct-acting antiviral agents. Am J Transplant 2016;16:1588-95.

2. Ellingson K, Seem D, Nowicki M, Strong DM, Kuehnert MJ. Estimated risk of human immunodeficiency virus and hepatitis C virus infection among potential organ donors from 17 organ procurement organizations in the United States. Am J Transplant 2011;11:1201-8.

3. Levitsky J, Formica RN, Bloom RD, et al. The American Society of Transplantation consensus conference on the use of hepatitis $\mathrm{C}$ viremic donors in solid organ transplantation. Am J Transplant 2017 May 29 (Epub ahead of print).

4. Leithead JA, Rajoriya N, Gunson BK, Muiesan P, Ferguson JW. The evolving use of higher risk grafts is associated with an increased incidence of acute kidney injury after liver transplantation. J Hepatol 2014;60:1180-6.

DOI: 10.1056/NEJMc1709315

Correspondence Copyright @ 2017 Massachusetts Medical Society. 